Original Research Article

\title{
A prospective, double blind randomised controlled trial on efficacy of laparoscopic uterosacral nerve ablation as an alternative of pharmacotherapy in treatment of chronic pelvic pain
}

\author{
Beenu Kushwah ${ }^{1}$, Devendra Singh Kushwah ${ }^{2}$, Aparna Pandey ${ }^{3}$
}

${ }^{1}$ Department of Gynecology, S.S. Medical College, Rewa, Madhya Pradesh, India ${ }^{2}$ Department of Pharmacology, Gajra Raja Medical College, Gwalior, Madhya Pradesh, India ${ }^{3}$ Department of Obstetrics and Gynaecology, S. S. Medical College, Rewa, Madhya Pradesh, India

Received: 07 February 2018 Accepted: 12 February 2018

\section{*Correspondence to:}

Dr. Devendra Singh Kushwah, Email: dev_singh433@ yahoo.com

Copyright: (C) the author(s), publisher and licensee Medip Academy. This is an openaccess article distributed under the terms of the Creative Commons Attribution NonCommercial License, which permits unrestricted noncommercial use, distribution, and reproduction in any medium, provided the original work is properly cited.

\begin{abstract}
Background: Chronic Pelvic Pain (CPP) is one of the commonest symptomatology in gynaecologist's outpatient clinics. CPP has a profound impact on a woman's health and quality of life, including an economic impact through loss of working hours. Treatment for chronic pelvic pain is often unsatisfactory. Present study compares Laparoscopic Uterosacral Nerve Ablation (LUNA) with laparoscopy without pelvic denervation in patients presenting with chronic pelvic pain to our outpatient clinic.

Methods: It was a Randomised Controlled Trial Study. After considering inclusion and exclusion criteria, 120 patients were selected, out of which 60 (Group I) had undergone diagnostic laparoscopy and 60 (Group II) had undergone diagnostic laparoscopy with LUNA.

Results: The overall success rate for group I and group II were 80\%, 78.3\% and $66.6 \%$ versus $85 \%, 81.6 \%$, and $83.3 \%$ at 3,6, and 12 months, respectively. However, on subgroup analysis it was found that in patients suffering from Congestive Dysmenorrhoea, there was a significant difference in success rate of both the groups.

Conclusions: It was found in present study that there was a benefit for patients with dysmenorrheal, further research in this area is desirable to reach towards a discrete conclusion regarding the benefits of LUNA in patients of CPP.
\end{abstract}

Keywords: Chronic pelvic pain, CPP, Dysmenorrhoea, Diagnostic laproscopy, Laproscopic uterosacral nerve ablation, LUNA

\section{INTRODUCTION}

Chronic pelvic pain (CPP) is defined as intermittent or constant pain in the lower abdomen or pelvis of at least 6 months duration, not completely relieved by medical treatment, not occurring exclusively with menstruation or intercourse and not associated with pregnancy. It is a symptom, not a diagnosis; dysmenorrhoea, deep dyspareunia, and intermenstrual pain constitute its main symptom complex. ${ }^{1} \mathrm{CPP}$ is one of the commonest symptomatology in gynaecologist's outpatient clinics. It accounts for $10-15 \%$ of office visits to gynecologists. ${ }^{2}$ There is a wide range of possible causes of chronic pelvic pain, most of which are difficult to diagnose and treat. The main gynecological diagnoses which can only be made at laparoscopy include, endometriosis, chronic pelvic 
inflammatory disease, and adhesions but pain may not always be causally related to these pathologies. ${ }^{1,2}$ The most common gastrointestinal cause of chronic pelvic pain is irritable bowel syndrome, possible genitourinary causes include interstitial cystitis, and the urethral syndrome. These conditions all have overlapping symptomatology that contributes to the difficulty in establishing a diagnosis. $^{3}$

In many women with chronic pelvic pain, no 'obvious' pathological explanation is found. Traditionally, pain in these women has often been attributed to psychological factors, an approach that is increasingly being recognized as unhelpful. Currently the main approaches to treatment include counseling or psychotherapy, attempts to provide reassurance using laparoscopy to exclude serious pathology, progesterone therapy such as with Medroxy Depot Progesterone Acetate (MDPA), and surgery to interrupt nerve pathways such as laparoscopic uterosacral nerve ablation (LUNA) and presacral neurectomy (PSN), or hysterectomy with or without removal of the ovaries. While less invasive, psychological approaches are time consuming and may not be acceptable to all women. Hormonal therapy is associated with side effects and impairs fertility during its use. ${ }^{4,5}$

Diagnostic laparoscopy is the gold standard to evaluate the underlying pathology and can establish a definitive diagnosis and modify the treatment without resorting to exploratory laparotomy. ${ }^{5}$ Nerve plexuses and parasympathetic ganglia in the uterosacral ligaments are thought to carry pain signals from the uterus, cervix and other pelvic structures. LUNA is performed after diagnostic laparoscopy and can be completed using lasers or electro-diathermy and has become increasingly used. Systematic reviews of the current research evidence on LUNA's efficacy are inconclusive. ${ }^{6,7}$ Clinician's beliefs about LUNA's efficacy vary widely and LUNA remains a controversial procedure. ${ }^{8-10}$ We conducted a randomized controlled trial comparing LUNA with laparoscopy without pelvic denervation in patients presenting with chronic pelvic pain to our outpatient clinic.

The objectives of the study were to evaluate the efficacy of LUNA in treatment of CPP- Rated using $10 \mathrm{~cm}$ Visual analogue scale (VAS) and to evaluate patient's satisfaction rate in CPP in both the groups.

\section{METHODS}

\section{Source of data}

Clinical material for present study comprises the patients with nonspecific chronic pelvic pain where other clinical symptoms and investigations are not conclusive, attending the Out-Patient Department and admitted to Department of Obstetrics and Gynecology of Shyam Shah Medical College associated Gandhi Memorial Hospital, fulfilling the inclusion criteria and given consents to be a part of study. A prior approval was obtained from Institutional Ethics Committee (Human Studies).

Design of the study was prospective, double blind randomised controlled study.

\section{Sample size}

The sample size for this trial has been estimated using the hypothesis that LUNA will alleviate pain symptoms (i.e. reduce pain scores on a VAS) more often than no intervention at one-year following diagnostic laparoscopy. As per previous studies $(8,10)$, considering $20 \%$ follow up lost it was calculated to be around 420 total patients but as this was a single centre study, we could recruit only 250 patients during the study period.

Duration of study was from $1^{\text {st }}$ August 2015 to $31^{\text {st }}$ July 2016 (12 months).

\section{Inclusion criteria}

- $\quad$ Pelvic pain of longer than 6-month duration

- Pain located within the true pelvis or between and below the anterior iliac crests.

- Associated functional disability

- $\quad$ Lack of response to medical treatment

\section{Exclusion criteria}

- $\quad$ Previous LUNA, Previous hysterectomy

- $\quad$ Mild, moderate and severe endometriosis (American Fertility Society score $>5$ )

- Previous surgery for endometriosis, Pelvic inflammatory disease

- Adnexal pathology

Initially total 250 patients were selected after detailed history and clinical examination 109 patients were excluded because of presence of obvious pathology and on 141patients DL was performed, 21 patients were further excluded from the study as they were found to have some kind of pathology duting DL, finally total 120 patients were included out of which 60 (Group I) had undergone DL only and 60 (Group II) had undergone DL with bilateral LUNA. Randomization was performed by computer generated numbers (Patients and the person who followed them, were kept blind regarding the group allocation) (Figure 1).

\section{Intervention}

Routine preparation was made for a diagnostic laparoscopy with the patient under general anaesthesia. Following pneumoperitoneum, a laparoscope was used to visualize the pelvis. Before embarking on operative laparoscopy, an anatomical pelvic assessment was performed to identify pelvic structures and pathology. Eligible patients were randomized into one of the study groups. In LUNA group two side ports of $5 \mathrm{~mm}$ on both 
the sides, were introduced while in control group only one side port of $5 \mathrm{~mm}$ was introduced. The posterior leaf of the broad ligament was carefully inspected to identify the course of the ureters, which, on rare occasions, could be particularly close to the uterosacral ligaments. The uterosacral ligaments were identified by manipulation of the uterus in the right and left lateral planes. Clear identification of the uterosacral ligaments was a prerequisite for treatment, and ablation of the ligament was carried out using 5-mm bipolar electrodiathermy using bipolar Meyerland forceps (the main unit of the diathermy is adjusted at $30 \mathrm{~W}$, and energy is applied for $5 \mathrm{~s}$ in order to deliver a dose power of coagulation $150 \mathrm{~J}$ to every uterosacral ligament), and then complete transaction of the uterosacral ligaments was done using a 5-mm curved scissors supplied with the ability to use monopolar electrodiathermy if needed. The ablation was started as close to the posterior aspect of the cervix as possible and continued for a minimum of $1 \mathrm{~cm}$ posterolaterally on either side.

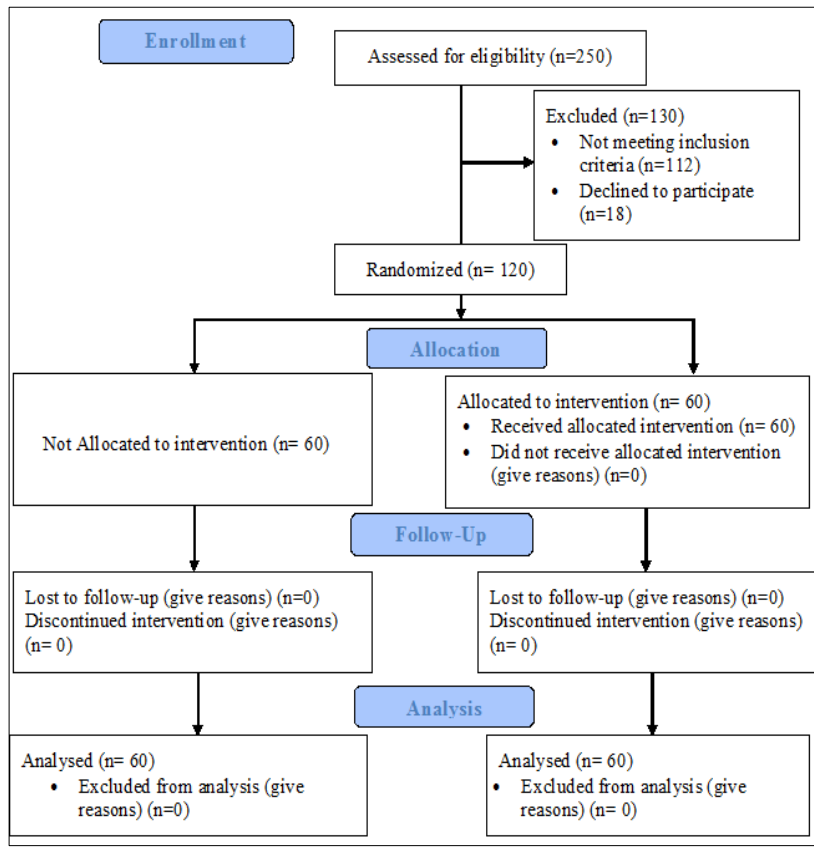

Figure 1: Consort diagram.

However, there is a potential problem in the maintenance of blinding in the LUNA trial. As mentioned earlier, patients allocated to have LUNA will have the standard operative laparoscopy with three ports (one $10 \mathrm{~mm}$ umbilical port and two $5 \mathrm{~mm}$ lateral ports), whereas patients allocated to the control group under normal circumstances would have standard diagnostic laparoscopy with two ports (one 10mm umbilical port and one $5 \mathrm{~mm}$ lateral or midline port) and it is easy for the patients to identify this difference. In control group, in order to maintain patient blinding, a sham $5 \mathrm{~mm}$ skin incision is made superficially in a lateral port site. This approach has been used in a previous trial of laparoscopic nerve ablation. ${ }^{9}$

\section{Statistical analysis}

All patients were followed up after 3, 6, and 9 months after the ablation. The effectiveness of the procedure was estimated using a $10 \mathrm{~cm}$ visual analog scale (VAS).

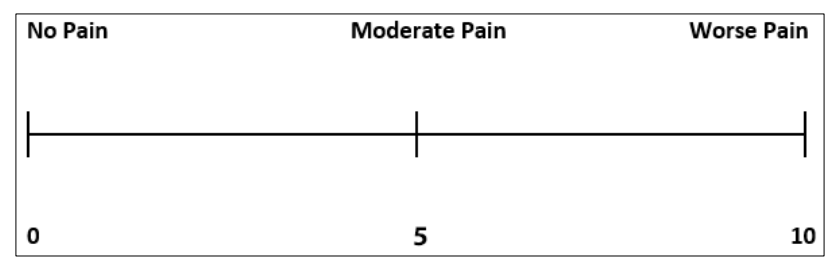

Figure 2: Visual analogue scale (3).

A VAS consists of a line, usually $10 \mathrm{cms}$ long whose ends are labelled as the extremes of pain - 'no pain' to 'worst pain'. A VAS may have specific points along the line that are labelled with intensity denoting adjectives or numbers. Patients were asked to rate their pain along the line that best represents the intensity of their pain. This distance between the no end and the mark provided by the patient is measured and this gives the pain intensity score.

In present study the VAS ratings were obtained at admission, 3 months, 6 months, and 9 months, for each of the types of pain: non-cyclical pain (pain at any time other than during periods or during intercourse), primary (spasmodic) dysmenorrhoea, secondary (congestive) dysmenorrhoea, and dyspareunia (pain during intercourse).

The patient's satisfaction was estimated by asking the patient a direct question (did the procedure improve your health status?, regarding the need for additional treatments, resource usage, days off work, and complications of surgery), and the patient's answers determine the degree of satisfaction.

- $\quad$ Excellent - 4

- Good- 3

- $\quad$ Average - 2

- No improvement - 1

Statistical analysis was performed on an IBM personal computer using SPSS statistical package for windows (SOSS, Inc, USA). Results were expressed as mean+ SD for quantitative characteristics, number, and percentage for qualitative characteristics. Among different groups, statistical comparison was made using chi-square $\mathrm{X}_{2}$ test or Fisher exact test for qualitative characteristics and one way ANOVA for numerical results among different groups. $\mathrm{P}$ value of $<0.05$ was considered as the level of significance.

\section{RESULTS}

After initial registration of 250 females, 141 were taken up for Diagnostic Laparoscopy (DL) out of which 21 were 
excluded because of presence of obvious pathology on DL, finally total 120 women, satisfying inclusion and exclusion criteria were included in the study.

Table 1 shows socio-demographic characteristics of the study population in both the groups which was comparable. Table 2 shows type of CPP (Clinical
Presentation) in both the groups, which was classified in four main groups and distribution of cases as per this classification was found to be comparable in both the groups. However, acyclic lower abdominal pain was the most common symptoms followed by spasmodic dysmenorrhoea in both groups.

Table 1: Socio-demographic characteristics of patients in both groups.

\begin{tabular}{|lllll|}
\hline & & Group I (control) $(\mathbf{N}=60)$ & Group II (study) $(\mathbf{N}=60)$ & P value \\
\hline Age & Range & $25-45$ & $26-45$ & $0.00 \mathrm{~S}^{*}$ \\
\hline (years) & $($ Mean+SD) & $32.25+3.63$ & $36.47+3.21$ & $\mathrm{NS}^{* *}, 0.52$ \\
\hline \multirow{2}{*}{ Weight $(\mathrm{kg})$} & Range & $45-75$ & $43-78$ & $\mathrm{NS}, 0.87$ \\
\cline { 2 - 5 } & $($ Mean \pm SD) & $58.98 \pm 8.16$ & $62.30+10.21$ & $152-175$ \\
\hline Height $(\mathrm{cms})$ & Range & $150-175$ & $1.63 \pm 0.79$ & $\mathrm{NS}, 0.107$ \\
\hline BMI $\left(\mathrm{kg} / \mathrm{cm}^{2}\right)$ & Range & $1.63 \pm .075$ & $19-27$ & \\
\hline \multirow{2}{*}{ Parity $(\mathrm{N})$} & Range & $20-25$ & $23.58 \pm 15.02$ & $\mathrm{NS}, 0.07$ \\
\hline
\end{tabular}

S*- Significant

NS**-Not Significant

Table 2: Categories of CPP, N (\%).

\begin{tabular}{|c|c|c|c|}
\hline & $\begin{array}{l}\text { Group I } \\
\text { (control) }\end{array}$ & $\begin{array}{l}\text { Group II } \\
\text { (study) }\end{array}$ & $\begin{array}{l}\mathbf{P} \\
\text { value }\end{array}$ \\
\hline $\begin{array}{l}\text { Acyclic Lower } \\
\text { abdominal pain } \\
\text { (AP) }\end{array}$ & $48(80 \%)$ & $45(75 \%)$ & $\begin{array}{l}\mathrm{NS}, \\
>0.05\end{array}$ \\
\hline $\begin{array}{l}\text { Congestive } \\
\text { dysmenorrhoea } \\
\text { (CD) }\end{array}$ & $6(10 \%)$ & $5(8.3 \%)$ & $\begin{array}{l}\mathrm{NS}, \\
>0.05\end{array}$ \\
\hline $\begin{array}{l}\text { Spasmodic } \\
\text { dysmenorrhoea } \\
\text { (SD) }\end{array}$ & $14(23.3 \%)$ & $\begin{array}{l}16 \\
(26.6 \%)\end{array}$ & $\begin{array}{l}\mathrm{NS}, \\
>0.05\end{array}$ \\
\hline $\begin{array}{l}\text { Deep dyspareunia } \\
\text { (D) }\end{array}$ & $3(5 \%)$ & $4(6.6 \%)$ & $\begin{array}{l}\mathrm{NS} \\
>0.05\end{array}$ \\
\hline
\end{tabular}

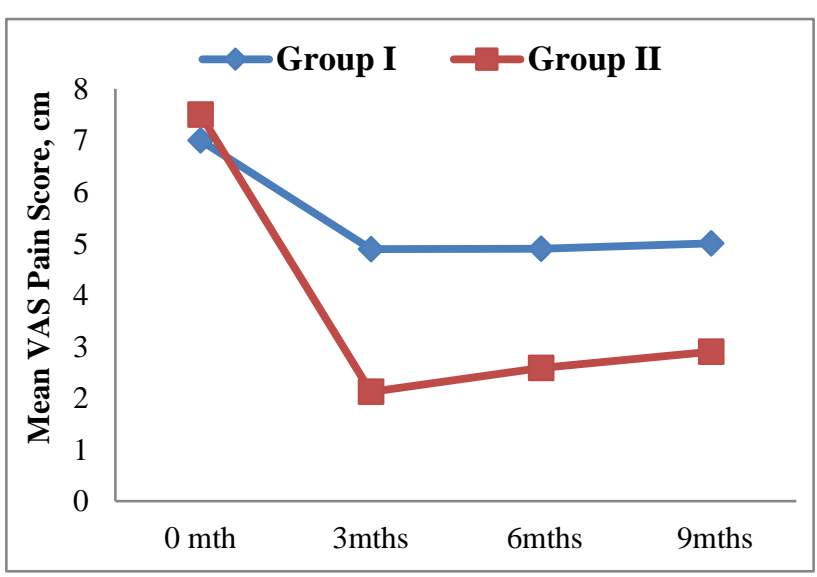

Table 3 shows incidence of complications in both the group and it was found that there was no major complication faced in both the groups.

Table 3: Operative details for both groups.

\begin{tabular}{|c|c|c|c|c|}
\hline & & Group I & $\begin{array}{l}\text { Group } \\
\text { II }\end{array}$ & $\begin{array}{l}P \\
\text { value }\end{array}$ \\
\hline \multirow{2}{*}{$\begin{array}{l}\text { Operative } \\
\text { time }\end{array}$} & $\begin{array}{l}\text { Range } \\
\text { (min) }\end{array}$ & $25-35$ & $28-40$ & \\
\hline & Mean \pm SD & $\begin{array}{l}31.23 \pm \\
8.07\end{array}$ & $\begin{array}{l}30.63 \pm \\
7.50\end{array}$ & $\begin{array}{l}\text { NS, } \\
0.67\end{array}$ \\
\hline \multirow{4}{*}{$\begin{array}{l}\text { Intra- } \\
\text { Operative } \\
\text { complicat } \\
\text { ions }\end{array}$} & Bleeding & $\begin{array}{l}2 / 60 \\
(3.33 \%)\end{array}$ & $\begin{array}{l}3 / 60 \\
(5 \%)\end{array}$ & $\begin{array}{l}\mathrm{NS}, \\
>0.05\end{array}$ \\
\hline & $\begin{array}{l}\text { Visceral } \\
\text { Injuries }\end{array}$ & 0 & 0 & None \\
\hline & $\begin{array}{l}\text { Vascular } \\
\text { injuries }\end{array}$ & 0 & 0 & None \\
\hline & $\begin{array}{l}\text { Conversion } \\
\text { to open } \\
\text { surgery }\end{array}$ & 0 & 0 & None \\
\hline
\end{tabular}

Difference in final outcome (in terms of relief of pain as measured by VAS Scale) was not found to be significant between group I and group II at 3, 6, and 12 months of follow-up $(\mathrm{P} \geq 0.05)$. The overall success rate for group I and group II were $80 \%, 78.3 \%$, and $66.6 \%$ versus $85 \%$, $81.6 \%$, and $83.3 \%$ at 3,6 , and 12 months, respectively (Figure 3 to Figure 6).

Figure 3: Congestive dysmenorrhoea. 


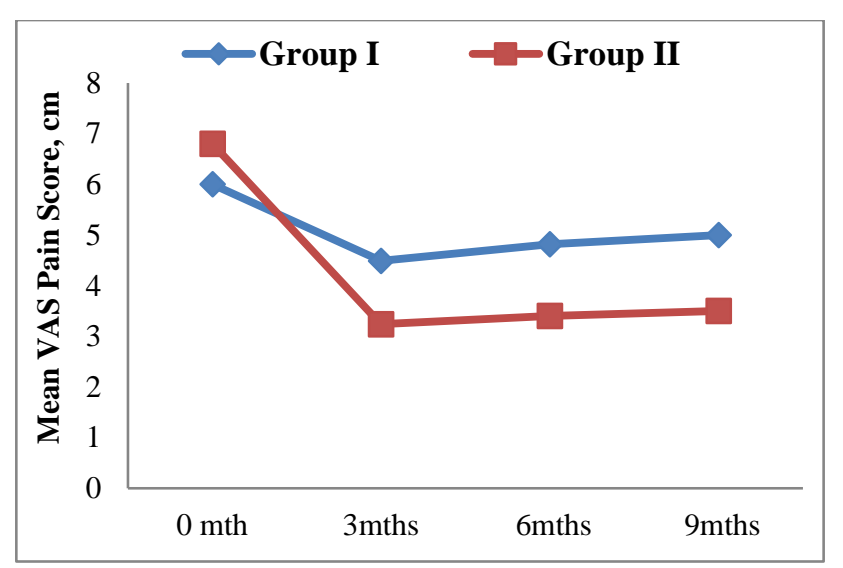

Figure 4: Dysparunia.

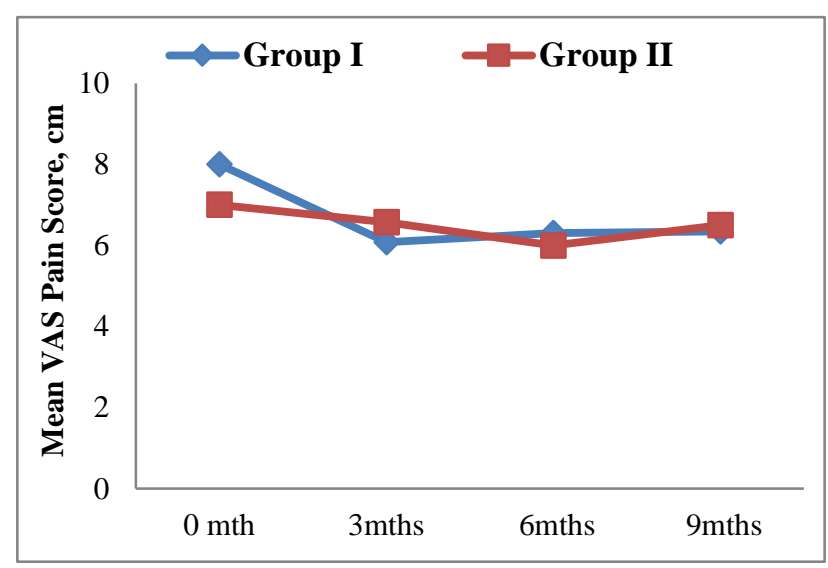

Figure 5: Spasmodic dysmenorrhoea.

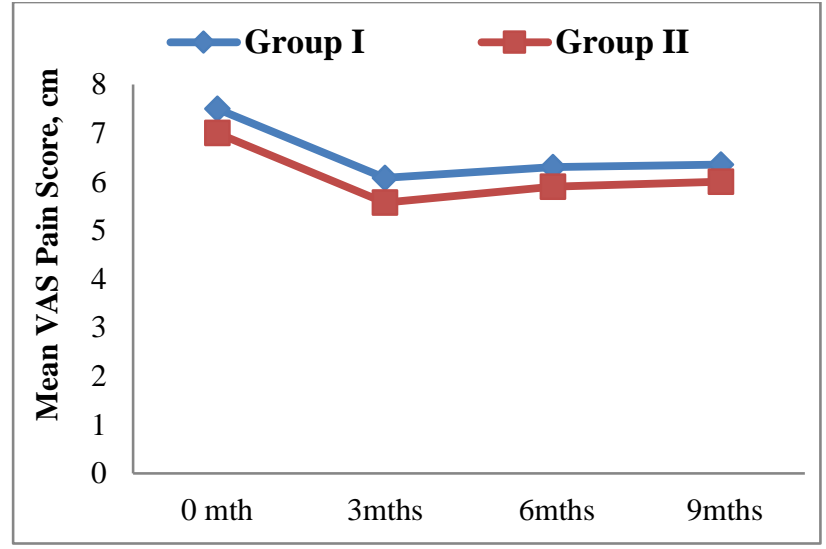

Figure 6: Acyclical lower abdominal pain.

However, on subgroup analysis it was found that in patients suffering from Congestive Dysmenorrhoea, there was a significant difference in success rate of both the groups $(\mathrm{P} \leq 0.005)$. In Dyspareunia group also, there was a difference in success rate between the groups but it was not found to be significant. In acyclic lower abdominal pain and Spasmodic Dysmenorrhoea category there was no difference in success rate between both the groups (Figure 3 to Figure 6).

Patients' satisfaction rate did not vary significantly between group I and group II at 3, 6, and 12 months follow-up $(\mathrm{P} \geq 0.05)$. The cumulative satisfaction rate was $76.6 \%, 75 \%$, and $71.6 \%$ versus $85 \%, 76.6 \%$, and $75 \%$ at 3 , 6, and 12 months between group I and group II, respectively (Table 4).

Table 4: Patients' satisfaction rate of the treatment during 3, 6, and 9 months follow-up in both groups.

\begin{tabular}{|lllllll|}
\hline \multirow{2}{*}{ Satisfaction rate } & Group I & \multicolumn{5}{c|}{ Group II } \\
& 3 months & 6 months & 9 months & 3 months & 6 months & 9 months \\
\hline \multirow{2}{*}{ Excellent } & $18 / 60$ & $17 / 60$ & $17 / 60$ & $24 / 60$ & $22 / 60$ & $20 / 60$ \\
& $(30 \%)$ & $(28.3 \%)$ & $(28.3 \%)$ & $(40 \%)$ & $(36.6 \%)$ & $(33.3 \%)$ \\
\hline \multirow{2}{*}{ Good } & $15 / 60$ & $14 / 60$ & $14 / 60$ & $13 / 60$ & $12 / 60$ & $13 / 60$ \\
& $(25 \%)$ & $(23.3 \%)$ & $(23.3 \%)$ & $(21.6 \%)$ & $(20 \%)$ & $(13.6 \%)$ \\
\hline \multirow{2}{*}{ Moderate } & $13 / 60$ & $13 / 60$ & $12 / 60$ & $11 / 60$ & $12 / 60$ & $12 / 60$ \\
& $(21.6 \%)$ & $(21.6 \%)$ & $(20 \%)$ & $(18.3 \%)$ & $(20 \%)$ & $(20 \%)$ \\
\multirow{2}{*}{ No improvement } & $14 / 60$ & $16 / 60$ & $17 / 60$ & $12 / 60$ & $14 / 60$ & $15 / 60$ \\
& $(23.3 \%)$ & $(26.6 \%)$ & $(28.3 \%)$ & $(20 \%)$ & $(23.3 \%)$ & $(25 \%)$ \\
\hline Cumulative & $46 / 60$ & $44 / 60$ & $43 / 60$ & $48 / 60$ & $46 / 60$ & $45 / 60$ \\
satisfaction rate & $(76.6 \%)$ & $(73.3 \%)$ & $(71.6 \%)$ & $(80 \%)$ & $(76.6 \%)$ & $(75 \%)$ \\
\hline
\end{tabular}

\section{DISCUSSION}

In the absence of pathology, there is no established treatment for CPP and therefore if conservative treatment has been unsuccessful, hysterectomy often becomes the final resort. As laparoscopy is associated with lesser morbidity, using it to make ablation of the nerve plexuses and ganglions in the uterosacral nerve ablation (LUNA) seems to be an attractive option. Some recent reports of randomised controlled studies have justified some role of LUNA in treatment of CPP. ${ }^{6,8}$ But systematic reviews and recent Cochrane reviews have stated that the currently 
available research evidence on LUNA is inconclusive and therefore further research is required among patients in different communities with different demographic and clinical characteristics. ${ }^{5,7}$

\section{Clinical presentation of study population}

As per Table 2, it is clear that acyclic lower abdominal pain was the most common presenting symptom followed by spasmodic dysmenorrhoea which is comparable to other studies. ${ }^{6,7}$ Deep dyspareunia was the least common symptom in both the groups.

\section{Comparison of total operative time, per-operative complications in both the group}

In both the group, mean operative time was comparable and it was 31.23 minutes in group I and 30.63 minutes in group II, which is comparable to other studies. ${ }^{6,7}$

Fever was the most common post-operative complication in both the groups which was presented within 48 hours of surgery and responded to the standard management. Constipation and urinary urgency was other common postoperative complaints which responded to the standard treatment and resolve by the time of discharge of patient from the hospital. These findings are comparable to other studies. ${ }^{6,7}$ Among intra-operative complication, minimal bleeding (blood loss $<50 \mathrm{ml}$ ) was the most common problem which was encountered in both the groups. In both the groups maximum of the study population return back to normal lifestyle within one week after the LUNA.

\section{Efficacy of LUNA in the treatment of CPP}

In the present study, there was no statistically significant difference as regards the efficacy and the overall success rate between group I and group II at 3, 6, and 9 months of follow-up $(\mathrm{P} \leq 0.05)$. This is in agreement with the results of other studies, in which LUNA was used to treat patients with $\mathrm{CPP}^{8,9}$ A review reported that there were no significant differences overall in pain relief between women treated with LUNA and controls (women treated with diagnostic laparoscopy or conservative surgery alone) as pain relief up to 6 months. In a recent randomized, controlled trial, 60 women were studied with CPP treated with LUNA or vaginal uterosacral nerve resection with a follow-up till 9 months, there were no significant differences between the two study groups with regard to pain relief. ${ }^{6,8}$ The same results were obtained from recent meta-analysis. $^{9}$ Also, in the most recent multicentric, randomized, controlled trial including 487 women with CPP lasting longer than 6 months without or with minimal endometriosis, adhesions, or pelvic inflammatory disease, concluded that after a median follow-up of 69 months, there were no significant differences reported on the visual analog pain scales for the worst pain between the LUNA group and the no LUNA group. ${ }^{6}$
A very interesting observation which was found in our trial is that on subgroup analysis success rate of LUNA proved out to be significantly higher in Congestive Dysmenorrhoea group; it was also higher in Dyspareunia group but was not statistically significant (Figure 3 to Figure 6), this finding corroborates with one other trial too. 5

\section{Satisfaction rate of patients in both the group}

As per Table 4, the cumulative satisfaction rate was $76.6 \%$, $75 \%$, and $71.6 \%$ versus $85 \%, 76.6 \%, 75 \%$ and at $3,6,9$ months between group I and group II, respectively $(\mathrm{P} \leq 0.05)$. This result goes hand in hand with the overall satisfaction rate in the meta-analysis study and other studies. ${ }^{5,10}$

\section{CONCLUSION}

Overall LUNA did not improve CPP. However, on subgroup analysis it did find improvement in CPP of those women who had Congestive Dysmenorrhoea as their chief complaint, A Cochrane review and another study also suggested a subgroup benefit for patients with dysmenorrheal, therefore further research in this area is highly desirable to reach towards a discrete conclusion regarding the benefits of LUNA in patients of CPP.

Funding: No funding sources

Conflict of interest: None declared

Ethical approval: The study was approved by the Institutional Ethics Committee

\section{REFERENCES}

1. Shin JH, Howard FM; Management of chronic pelvic pain: Curr Pain Headache Rep. 2011 Oct;15(5):37785.

2. Ahangari A. Prevalence of Chronic Pelvic Pain Among Women: An Updated Review. Pain Physician. 2014;17:E141-E147.

3. Yosef A, Ahmed A, Hussaini A, Abdellah M, Cua G. Chronic pelvic pain: Pathogenesis and validated assessment. Middle East Fertility Society Journal, Dec 2016;21(4):205-21.

4. Royal College of Obstetricians and Gynaecologists. The initial management of chronic pelvic pain. Greentop Guideline No. 41 May 2012.

5. Proctor ML, Latthe PM, Farquhar CM, Khan KS, Johnson NP. Surgical interruption of pelvic nerve pathways for primary and secondary dysmenorrhea Cochrane Database of Systematic Reviews. The Cochrane Collaboration; 2007 Issue 3.

6. Daniels J, Gray R, Hills RK, Latthe P, Buckley L, Gupta J, et al. LUNA Trial Collaboration Laparoscopic uterosacral nerve ablation for alleviating chronic pelvic pain: a randomized controlled trial. JAMA. 2009 Sep 2;302(9):955-61.

7. National Institute for Clinical Excellence (NICE). Laparoscopic uterine nerve ablation (LUNA) for 
chronic pelvic pain. IP Guidance Number: IPG234. London, UK: NICE; October 2007 Available at: http://www.nice.org.uk/nicemedia/pdf/IPG234Guida nce.pdf. Accessed February 28, 2015.

8. Palomba S, Russo T, Falbo A. Laparoscopic uterine nerve ablation versus vaginal uterosacral ligament resection in postmenopausal women with intractable midline chronic pelvic pain: a randomized study. Eur J Obstet Gynaecol. 2006;129:84-91.

9. Xiong T, Daniels J, Middleton L, Champaneria R, Khan KS, Gray R, et al. International LUNA IPD Meta-analysis Collaborative Group: meta-analysis using individual patient data from randomised trials to assess the effectiveness of laparoscopic uterosacral nerve ablation in the treatment of chronic pelvic pain:
a proposed
protocol.
BJOG.
2007

Dec;114(12):1580e1-7.

10. Dunselman GAJ, Vermeulen N, Becker C. ESHRE guideline: management of women with endometriosis. Hum Reprod. 2014;29:400e12.

Cite this article as: Kushwah B, Kushwah DS, Pandey A. A prospective, double blind randomised controlled trial on efficacy of laparoscopic uterosacral nerve ablation as an alternative of pharmacotherapy in treatment of chronic pelvic pain. Int J Basic Clin Pharmacol 2018;7:473-9. 